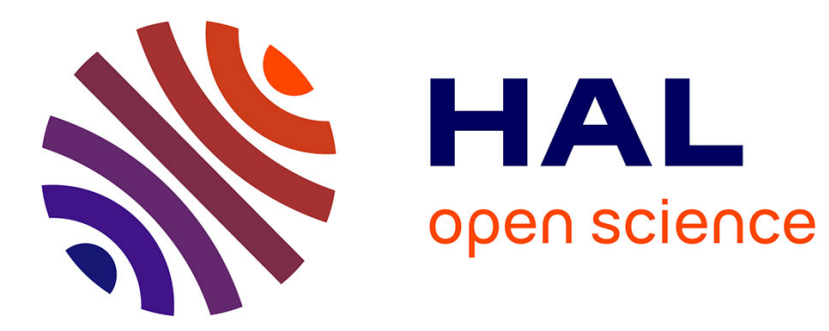

\title{
DEGREE OF ORDER IN QUENCH-CONDENSED ALLOYS STUDIED BY RESISTIVITY AND THE PHONON SPECTRUM FROM TUNNELLING
}

T. Claeson, C. Granqvist

\section{- To cite this version:}

T. Claeson, C. Granqvist. DEGREE OF ORDER IN QUENCH-CONDENSED ALLOYS STUDIED BY RESISTIVITY AND THE PHONON SPECTRUM FROM TUNNELLING. Journal de Physique Colloques, 1974, 35 (C4), pp.C4-253-C4-255. 10.1051/jphyscol:1974447 . jpa-00215638

\section{HAL Id: jpa-00215638 \\ https://hal.science/jpa-00215638}

Submitted on 1 Jan 1974

HAL is a multi-disciplinary open access archive for the deposit and dissemination of scientific research documents, whether they are published or not. The documents may come from teaching and research institutions in France or abroad, or from public or private research centers.
L'archive ouverte pluridisciplinaire HAL, est destinée au dépôt et à la diffusion de documents scientifiques de niveau recherche, publiés ou non, émanant des établissements d'enseignement et de recherche français ou étrangers, des laboratoires publics ou privés. 


\title{
DEGREE OF ORDER IN QUENCH-CONDENSED ALLOYS STUDIED BY RESISTIVITY AND THE PHONON SPECTRUM FROM TUNNELLING (*)
}

\author{
T. CLAESON and C. G. GRANQVIST \\ Physics Department \\ Chalmers University of Technology \\ Fack, S-402 20 Gothenburg, Sweden
}

\begin{abstract}
Résumé. - Nous avons pu utiliser la forme de la structure induite par les phonons dans les courbes d'effet tunnel supraconducteur pour classer le degré d'ordre structural dans des films d'alliages à base de plomb. Les films ont été condensés à $0,4 \mathrm{~K}$ et étudiés à l'état de dépôts et recuits à 30,100 et $300 \mathrm{~K}$. Les températures de transformation d'un état à l'autre ont pu être identifiées avec celles où il se produit une discontinuité dans la variation de la résistivité avec la température. Ces températures sont reliées aux points de fusion des solutés purs. Des modes de phonons localisés n'ont pu être observés que dans $\mathrm{PbIn}$, et seulement dans des films avec des grains relativement grands. Il est difficile d'expliquer pourquoi on n'observe aucun mode d'impureté dans $\mathrm{PbSn}$.

Abstract. - The shape of phonon induced structure in superconductive tunnelling curves could be used to classify the degree of structural order in lead alloy films. The films were condensed at $0.4 \mathrm{~K}$ and studied as deposited and after anneals to 30,100 and $300 \mathrm{~K}$. Temperatures of transformation from one state to another could be identified with those where steps occurred in resistance vs. temperature curves. These temperatures scale with the melting points of the pure solutes. Localized phonon modes could be observed in PbIn only, and solely in films with relatively large grains. It is difficult to explain why no impurity modes are seen in $\mathrm{PbSn}$.
\end{abstract}

A metallic film deposited upon a very cold substrate has a very disordered, or even amorphous structure. This has been verified by X-ray and electron diffraction $[1,2]$. If the resistance of such a film is measured while the film is heated, a curve similar to the one in figure 1 is obtained. The film resistivity drops more in some temperature regions than in others as the structural order in the film increases $[1,2]$.

We have utilized the method of superconducting tunnelling to study the phonon spectra of lead alloy films possessing different degrees of order. We will show that the latter property is important for the appearance of localized phonon modes. The way the phonon distribution looks like can be used to characterize the degree of order in the film.

Tunnelling into strong coupling superconductors is a powerful method to study the phonon distribution [3]. There is a very good correspondence between structure in the second voltage derivative of the tunnel current versus bias voltage, $\mathrm{d}^{2} I / \mathrm{d} V^{2}$ vs. $V$, and critical points in the phonon density of states [4]. Lead is the prime example of a metal giving strong phonon induced structure [3].

We have quench-condensed $\mathrm{Pb}$ alloys (with 10 at. \%

(*) Supported by the Swedish Natural Science Research Council. of either $\mathrm{Na}, \mathrm{Mg}, \mathrm{Zn}, \mathrm{Ga}, \mathrm{Ge}, \mathrm{Ag}, \mathrm{Cd}, \mathrm{In}, \mathrm{Sn}, \mathrm{Sb}$, or $\mathrm{Te}$ ) upon a substrate cooled to $0.4 \mathrm{~K}$ [5]. The phonon induced structure for these was generally very smeared (except for the In alloy). A peak due to longitudinal type modes was clearly resolved, while the transversal ones were very ill-defined. As the order increased by anneals to successively higher temperatures, the structure grew sharper and details appeared as shown in figure 2 .

A crystalline state with small grains is characterized by both transversal and longitudinal type phonon peaks. However the phonon life-times are still short. No charasteristic split of the transversal phonon distribution into two peaks $[3,6]$ can be noticed, and no localized phonon modes can be traced for $\mathrm{PbIn}$. As the order is increased further, i. e. when the grains grow (which they do in a limited temperature range, compare Fig. 1), van Hove singularities and localized modes appear. The different characters are summarized in figure 1 .

The temperatures of transformations from one structural state (as characterized by the phonon structure) to another could be determined from resistance vs. temperature curves during annealing [7]. Three different transformations were noted : (i) One at low temperature from one amorphous (or so finely crystalline that the phonon distribution looked liquid 


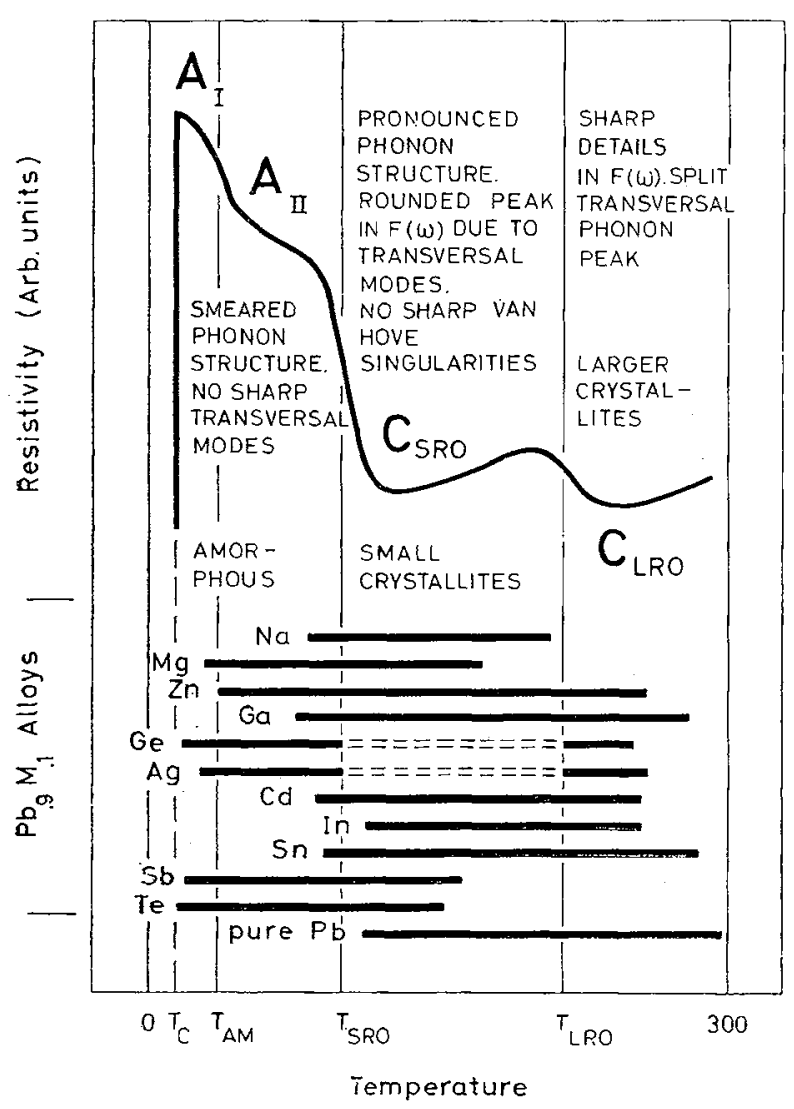

FIG. 1. - The resistivity of a quench-condensed lead alloy film decreases as the film is warmed. The reduction is concentrated to certain transformation regions. This is due to transformations occurring between states with different degrees of lattice order as characterized by their phonon distributions (AI, $A_{I I}$ : amorphous ; $C_{S R O}$ : crystalline, short range order ; $C_{L R O}$ : crystalline, long range order). All the transformations do not necessarily occur in every alloy. The lower part of the figure indicates which portion of the idealized "master" curve that is run through during anneals to room temperature. For Ge and $\mathrm{Ag}$ the films transform directly from an amorphous to a long range ordered state.

like) to another. (ii) Another at an intermediate temperature that took the film from an amorphous to a short range ordered crystalline one. (iii) In a third transformation, finally, the grains grow. The transformations that appeared in the different alloys are indicated in the lower part of figure 1.

The transformation temperatures were correlated with different physical and chemical properties of the impurity elements, and we found a strong correlation to the melting temperature. Particularly this is the case for the most pronounced of the transformations, the one that takes the film from an amorphous (as defined by the phonon spectrum) to a crystalline state. This is shown in figure 3 . Of course, the melting temperature of an element can be correlated in its turn with many other of its properties.

Our original motive of the investigation was to study localized phonon modes. As a sufficiently light atom is dissolved in a host matrix, it can vibrate

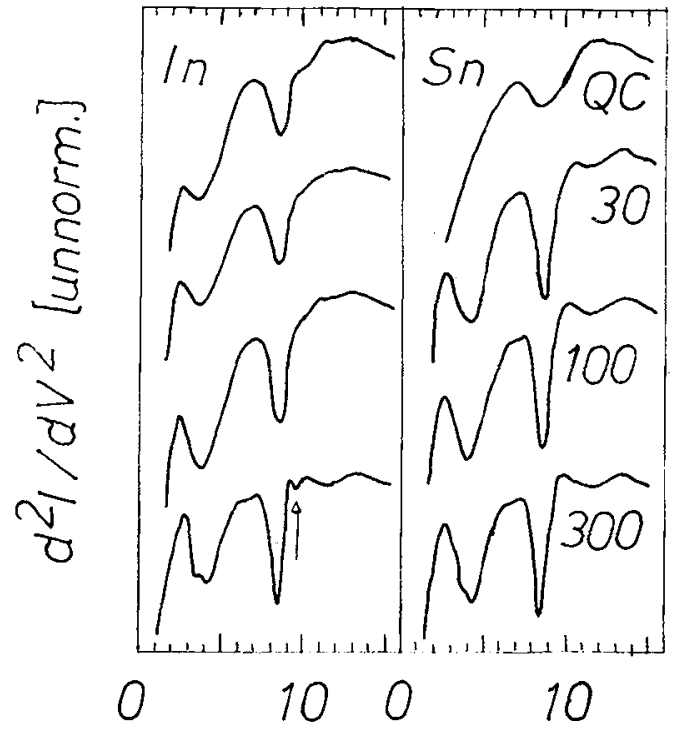

\section{Bias from energy gap [meV]}

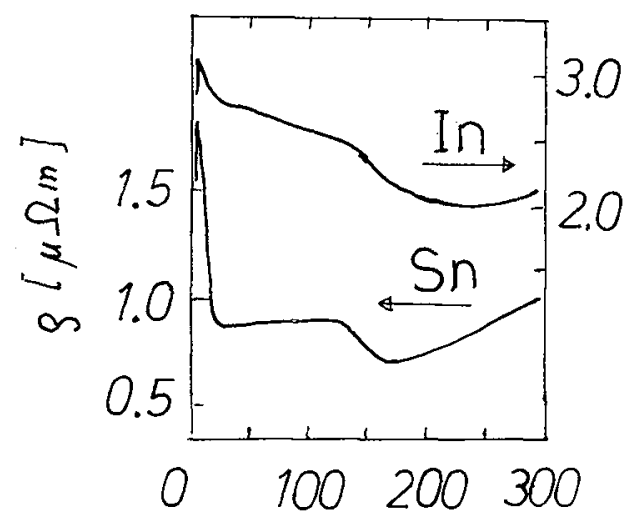

FIG. 2. - The second voltage derivative of the tunnelling current versus bias is shown in the upper part of the figure, $\mathrm{Pb} .{ }_{9} \mathrm{In} .1$ and $\mathrm{Pb} .{ }_{9} \mathrm{Sn}_{1}$ films are investigated directly after a quench-condense upon a single crystal quartz substrate kept below $0.4 \mathrm{~K}$ and after anneals to 30,100 and $300 \mathrm{~K}$. Note the appearance of localized phonon modes (the arrow) for the $\mathrm{Pb} .9 \mathrm{In} .1$ film after it has been annealed above about $200 \mathrm{~K}$. Such local modes could not be detected for the Sn alloy. The resistivities of the film during warming are displayed in the lower part.

with a frequency higher than those of the matrix. These phonon modes are localized in space [8]. In the case of PbIn, localized phonons have been studied previously by the tunnelling method [9-11]. It is difficult to dissolve other elements in Pb. The only cases where one has a substantial solubility [12] are for In $(68 \%)$, Sn $(3 \%)$, and $\mathrm{Na}(1.8 \%)$. It has been reported, though, that a considerably higher solubility has been achieved in metastable solutions [13-14]. Therefore we had good hopes of obtaining forced solutions in our quench-condensed films. However, 


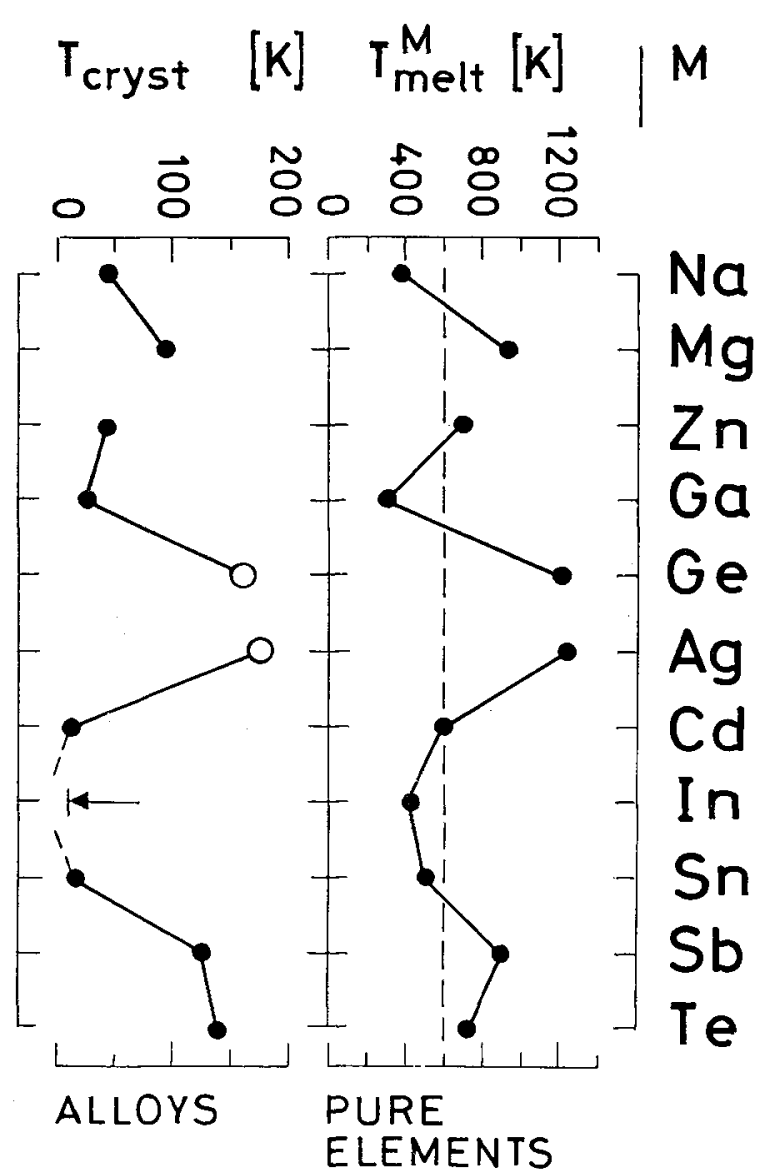

FIG. 3. - The temperature for the transformation from an amorphous to a crystalline state $\left(T_{\text {cryst }}\right)$ is indicated for several $\mathrm{Pb} .9 \mathrm{M}_{11}$ alloys. Note the strong correlation to the melting temperature of the pure solute $\left(T_{\mathrm{me} 1 \mathrm{it}}^{\mathrm{M}}\right)$ ! we did not see any localized modes in any lead-based alloy, but $\mathrm{PbIn}$.

We have discovered that a certain amount of structural order is necessary for the localized modes to appear separated from the main distribution [15]. In PbIn they become evident first in long range ordered films (cf. Fig. 2). In several of the alloys the films have not reached this structural state even after annealing at room temperature. Hence we can explain why no local modes are seen in the $\mathrm{Na}, \mathrm{Mg}, \mathrm{Sb}$ and Te alloys.

Furthermore, at the relatively high temperature, where the film orders, impurities precipitate when the solubility limit is exceeded. This can easily be seen in the $\mathrm{d}^{2} I / \mathrm{d} V^{2}$ vs. $V$ curves which look like pure $\mathrm{Pb}$ ones. If we assume that we need about 0.5 at. \% of an impurity to get a detectable signal (as for PbIn) [11], we can on this account explain why no local modes are seen in the $\mathrm{Zn}, \mathrm{Ga}, \mathrm{Ge}, \mathrm{Ag}$ and $\mathrm{Cd}$ alloys,

But still there is the case of $\mathrm{Sn}$ left to explain ! $\mathrm{Sn}$ is dissolved in $\mathrm{Pb}$ to an extent $[12,14]$ which should well exceed the observational limit. The film should also be a well ordered state as indicated by figure 2 . The atomic masses of Sn and In are very similar, they seem to both be dissolved substitutionally in $\mathrm{Pb}$ [16], and they both have similar electron-phonon coupling strengths [3]. Hence $\mathrm{Sn}$ ought to give rise to local phonons similar to those of $\mathrm{In}$ in $\mathrm{Pb}$. There are differences between In and Sn, though, that ought to be pointed out. They have different valency and their solubilities in $\mathrm{Pb}$ differ with an order of magnitude. The solution to the mystery of the lost Sn impurity modes might be connected to these facts.

References

[1] RüHL, W., Z. Phys. 138 (1954) 121 ;

Buckel, W., Z. Phys. 138 (1954) 136;

BüLow, H. and BuCKel, W., Z. Phys. 145 (1956) 141.

[2] Mader, S., J. Vac. Sci. Tech. 2 (1965) 35;

MADER, S., Nowick, A. S. and WIDMER, H., Acta Met. 15 (1967) 203;

MAder, S. and Nowick, A. S., Acta Met, 15 (1967) 215.

[3] McMmlan, W. L. and Rowell, J. M., in Superconductivity (ed. R. D. Parks, Marcel Dekker, New York) 1969, Vol. 1, p. 561.

[4] Scalapino, D. J. and Anderson, P. W., Phys. Rev. 133 (1964) A291;

see also figure 7 of Claeson, T. and Grimvall, G., $J$. Phys. Chem. Solids 29 (1968) 387.

[5] Granquist, C. G. and Claeson, T., J. Low Temp. Phys. 10 (1973) 735 ; 13 (1973) 1.

[6] Stedman, R., Armqvist, L. and Nilsson, G., Phys. Rev. 162 (1967) 549.

[7] Grangvist, C. G. and Claeson, T., Thin Solid Films 16 (1973) 65.
[8] Maradudin, A. A., J. Phys. C: Solid State Physics (eds. H. Ehrenreich, F. Seitz and D. Turnbull, Acad. Press, New York) 18 (1966) 273; 19 (1967) 1;

P. Dean, Rev. Mod. Phys. 44 (1972) 127.

[9] Rowell, J. M., McMillan, W. L. and Anderson, P. W., Phys. Rev. Lett. 19 (1965) 633.

[10] Adler, J. G., Jackson, J. E. and Chandrasekhar, B. S., Phys. Rev. Lett. 16 (1966) 53.

[11] Soon, B. R., Phys. Rev. B 6 (1972) 136.

[12] Hansen, M. and Anderko, K., The Constitution of Binary Alloys, 2nd ed. (McGraw-Hill, New York) 1958.

[13] Natkaniec, I., Parlinski, K., JaniK, J. A., Bajorek, A. and SUDNIK-HRYNKIEwICZ, M., in Neutron Inelastic Scattering (ed. by Int. Atomic Energy Agency, Vienna) 1968, Vol. 1, p. 65.

[14] Livingston, J. D., J. Appl. Phys. 34 (1963) 3028.

[15] Granquist, C. G. and Claeson, T., Phys. Kond. Mater. 16 (1973) 113.

[16] KuČERA, J. and STRÁnskÝ, K., Can. Met. Quart. 8 (1969) 91.

Seith, W. and LaIRd, J. G., Z. Metalkunde 24 (1932) 193. 